\title{
Primary Care Visit Regularity and Patient Outcomes: an Observational Study
}

\author{
Adam J. Rose, MD MSc FACPl, 2, Justin W. Timbie, $P h D^{3}$, Claude Setodji, $P h D^{4}$, \\ Mark W. Friedberg, MD MPP ${ }^{1,5}$, Rosalie Malsberger, $\mathrm{MS}^{7}$, and Katherine L. Kahn, MD ${ }^{6,7}$
}

${ }^{1}$ RAND Corporation, Boston, MA, USA; ${ }^{2}$ Boston University School of Medicine, Boston, MA, USA; ${ }^{3}$ RAND Corporation, Arlington, VA, USA; ${ }^{4}$ RAND Corporation, Pittsburgh, PA, USA; ${ }^{5}$ Harvard Medical School, Boston, MA, USA; ${ }^{6}$ RAND Corporation, Santa Monica, CA, USA; ${ }^{7}$ David Geffen School of Medicine at UCLA, Los Angeles, CA, USA.

BACKGROUND: Regular primary care visits may allow an opportunity to deliver high-value, proactive care. However, no previous study has examined whether more temporally regular primary care visits predict better outcomes. OBJECTIVE: To examine the relationship between the temporal regularity of primary care (PC) visits and outcomes.

DESIGN: Retrospective cohort study.

PARTICIPANTS: We used Medicare claims for 378,862 fee-for-service Medicare beneficiaries, who received PC at 1328 federally qualified health centers from 2010 to 2014 . MAIN MEASURES: We created five beneficiary groups based upon their annual number of PC visits. We further subdivided those groups according to whether PC visits occurred with more or less regularity than the median value. We compared these 10 subgroups on three outcomes, adjusting for beneficiary characteristics: emergency department (ED) visits, hospitalizations, and total Medicare expenditures. We also aggregated to the clinic level and divided clinics into tertiles of more, less, and similarly regular to predicted. We compared these three groups of clinics on the same three outcomes of care.

KEY RESULTS: Within each visit frequency group, beneficiaries in the subgroup with fewer regular visits had more ED visits, more hospitalizations, and higher costs. Among beneficiaries with the most frequent PC visits, the less regular subgroup had more ED visits (1.70 vs. 1.31 per person-year), more hospitalizations (0.69 vs. 0.57), and greater Medicare expenditures $(\$ 20,731$ vs. $\$ 17,430, p<0.001$ for all comparisons). Clinics whose $\mathrm{PC}$ visits were more regular than predicted also had better outcomes than other clinics, although the effect sizes were smaller.

CONCLUSIONS: Temporal patterns of PC visits are correlated with outcomes, even among beneficiaries who appear otherwise similar. Measuring the temporal regularity of PC visits may be useful for identifying beneficiaries at

Electronic supplementary material The online version of this article (https://doi.org/10.1007/s11606-018-4718-x) contains supplementary material, which is available to authorized users.

Received April 18, 2018

Revised September 17, 2018

Accepted October 18, 2018

Published online October 26, 2018 risk for adverse events, and as a barometer for and an impetus to clinic-level quality improvement.

KEY WORDS: quality of healthcare; temporally regular care; clinical practice variation; primary care; utilization; cost.

J Gen Intern Med 34(1):82-9

DOI: $10.1007 / \mathrm{s} 11606-018-4718-\mathrm{x}$

(C) Society of General Internal Medicine 2018

\section{INTRODUCTION}

Primary care is a key leverage point for transforming medical care and improving patient outcomes, especially for those with chronic disease. ${ }^{1}$ High-quality primary care contributes to improved health outcomes, ${ }^{2,3}$ reduced health disparities, ${ }^{4,5}$ and lower cost of care. ${ }^{6}$ The Chronic Care Model ${ }^{1,7}$ mentions regular primary care visits as an important ingredient for coordination and continuity of care. Regular visits to primary care could allow for more orderly and proactive delivery of preventive care and care management and could help avert adverse events such as emergency department (ED) visits and hospitalizations, especially among patients with chronic disease. Conversely, irregular primary care visits may allow an unaddressed clinical problem to worsen, culminating in an adverse event such as an ED visit (Fig. 1).

While regular and irregular visit patterns might be associated with a similar count of primary care visits, more regular visit patterns might allow for a more proactive and thoughtful approach to addressing issues before they become critical problems. Irregular visits, on the other hand, might indicate a pattern of missed appointments, urgent care visits, or other similar patterns that would be less productive for maintaining health. This supposition has not previously been studied. We hypothesized that after adjustment for beneficiary characteristics and frequency of visits, beneficiaries with more regular primary care visits would have fewer ED visits, fewer hospitalizations, and lower total Medicare expenditures. We further hypothesized that sites would vary on the regularity of primary care visits, even after adjusting for beneficiary characteristics, and that this site-level variation would predict these same outcomes. 

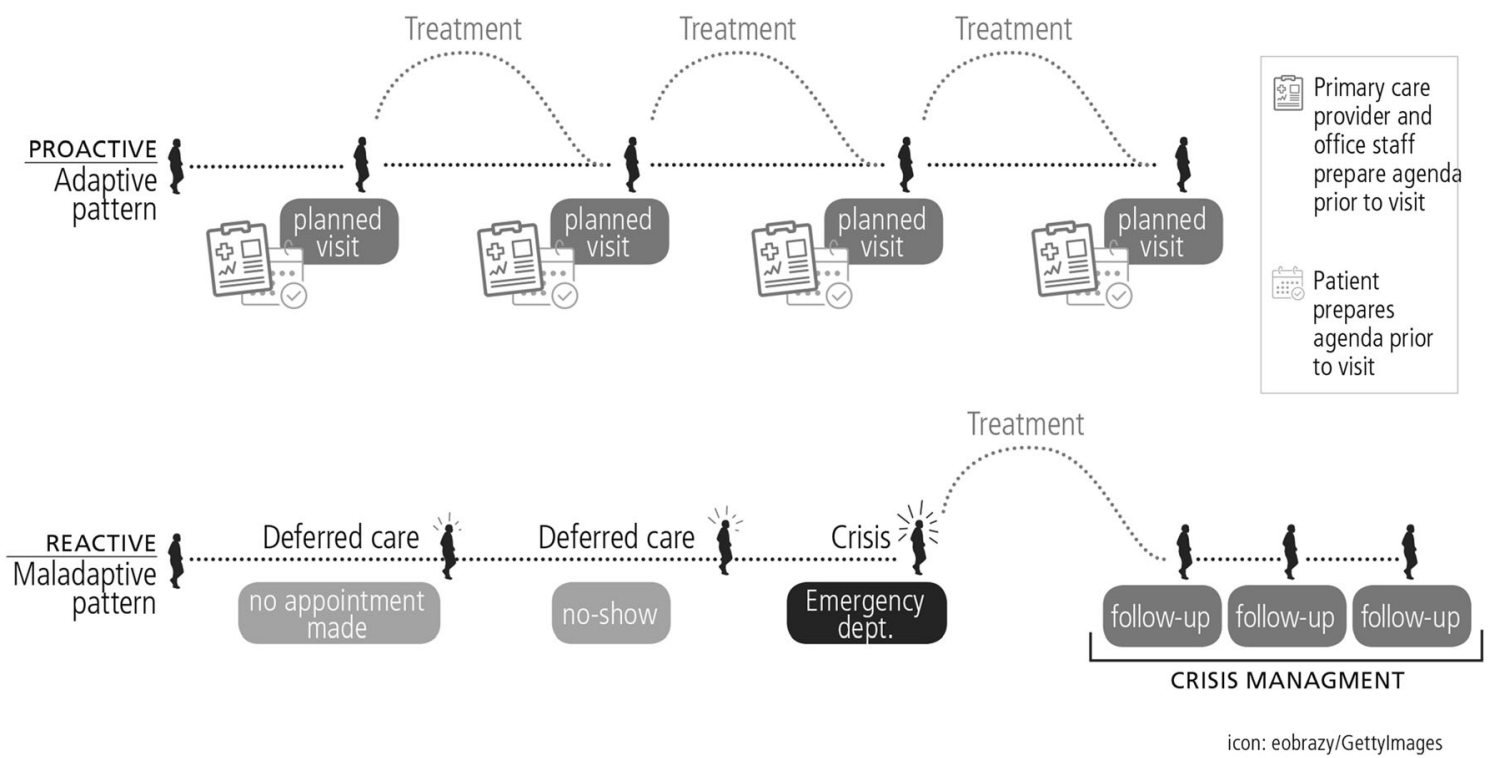

Figure 1 Proactive, temporally regular care may produce a similar number of visits as irregular and reactive care - but the visits can be better planned, and more effective at improving outcomes.

\section{METHODS}

\section{Sample}

The sample for this retrospective cohort study was drawn from a broader study of Medicare fee-for-service (FFS) beneficiaries who used services from one of 1330 federally qualified health centers (FQHCs) that participated in the Centers for Medicare \& Medicaid Services' (CMS's) FQHC Advanced Primary Care Practice (APCP) Demonstration from November 2011 through October 2014. ${ }^{8,9}$ The present study also used data from the prior year (November 2010 through October 2011) as a baseline period. Throughout this manuscript, we refer to the baseline year as year 0 , and the 3 years of the demonstration project as years $1-3$. The study was approved by the RAND Human Subjects Protection Committee.

The evaluation sample consists of 428,146 Medicare FFS beneficiaries who were attributed to one of these $\mathrm{FQHC}$ sites (including both demonstration and comparison sites) based on where they received the plurality of their primary care visits during year 0 , year 1 , or year 2 (whichever year they first met attribution criteria). Details of the attribution procedures are in Online Appendix A.

Medicare beneficiaries were included in the sample for this study if they were continuously enrolled in parts A and B, not in Medicare Advantage, and did not have end-stage renal disease during their first full year of data. To be included, beneficiaries also needed to have at least three primary care visits during year 0 , year 1 , and year 2 , with at least 180 days between the first and the last visit to an FQHC. After these sample requirements were applied, the cohort included 378,862 beneficiaries, each of which was attributed to a single FQHC site.

Because all outcomes were measured during year 3, 27,823 beneficiaries who died prior to year 3 were excluded from outcomes analyses. Beneficiaries who were alive and eligible for at least part of year 3 were retained, and outcomes (ED visits, hospitalizations, total Medicare expenditures) were prorated per month of eligibility. After these exclusions, 322,146 beneficiaries remained in the final sample.

\section{Analytic Steps for Categorizing Beneficiaries According to Their Primary Care Visits, Beneficiary Characteristics, and Clinic Characteristics}

Discrete analytic steps were implemented to test two study hypotheses. First, we tested the beneficiary-level hypothesis that beneficiaries with more regular PC visits would have better outcomes than beneficiaries with less regular PC visits. Next, we tested the site-level hypothesis that sites with more regular primary care visits than predicted would have better outcomes than sites with less regular primary care visits than predicted. Throughout our analyses, better outcomes are defined as fewer ED visits, fewer hospitalizations, and lower Medicare expenditures. The paragraphs that follow and Table 1 summarize seven discrete analytic steps.

Step 1: Divide the sample into five groups based on primary care visit frequency

We examined the univariate distribution of primary care visit frequencies among beneficiaries during years $0-2$. We identified five natural groupings, which included a large group with infrequent visits (the bottom $40 \%$ ), a relatively small group with extremely frequent visits (the top 5\%), and three roughly equal-size groups in between.

Step 2: Subdivide five groups into 10 groups based upon visit regularity 
Table 1 Summary of Analytic Steps

\begin{tabular}{|c|c|c|c|}
\hline $\begin{array}{l}\text { Step } \\
\text { number }\end{array}$ & Step title & Step methods & Result of step \\
\hline Step 1 & Visit frequency groups & $\begin{array}{l}\text { Categorize Medicare beneficiaries according to their } \\
\text { frequency of PC visits }\end{array}$ & $\begin{array}{l}5 \text { groups of beneficiaries stratified by frequency } \\
\text { of PC visits }\end{array}$ \\
\hline Step 2 & Visit regularity subgroups & $\begin{array}{l}\text { Sub-divide each of the } 5 \text { groups from Step } 1 \text { into } \\
\text { "regular" and "irregular" subgroups based on } \\
\text { regularity of PC visits }\end{array}$ & 10 subgroups of beneficiaries \\
\hline Step 3 & $\begin{array}{l}\text { Probability of being in } \\
\text { regular subgroup }\end{array}$ & $\begin{array}{l}\text { Use beneficiary demographic and clinical } \\
\text { characteristics to predict the probability of a } \\
\text { beneficiary having more than the median regularity } \\
\text { of PC visits }\end{array}$ & $\begin{array}{l}\text { Estimated probability (range } 0-1 \text { ) for each } \\
\text { beneficiary to be assigned to the regular subgroup }\end{array}$ \\
\hline Step 4 & $\begin{array}{l}\text { Expected site-level propor- } \\
\text { tion of beneficiaries with } \\
\text { regular visits }\end{array}$ & $\begin{array}{l}\text { Categorize sites based on whether they had more or } \\
\text { fewer beneficiaries in the regular PC subgroup than } \\
\text { would be predicted }\end{array}$ & $\begin{array}{l}\text { Calculated proportion (range } 0-100 \% \text { ) of } \\
\text { beneficiaries at each site, within each PC } \\
\text { frequency group, predicted to be in the regular } \\
\text { subgroup }\end{array}$ \\
\hline Step 5 & $\begin{array}{l}\text { Site-level comparison of } \\
\text { observed and expected }\end{array}$ & $\begin{array}{l}\text { Compare the observed proportion of beneficiaries in } \\
\text { the regular subgroup at each site with the expected } \\
\text { proportion, to generate an observed minus expected } \\
\text { (O-E) score }\end{array}$ & $\begin{array}{l}\text { Each site characterized as having more, fewer, or } \\
\text { about the same proportion of beneficiaries in the } \\
\text { regular subgroup than predicted }\end{array}$ \\
\hline Step 6 & Beneficiary-level analyses & $\begin{array}{l}\text { Test the beneficiary-level hypothesis that beneficia- } \\
\text { ries with more regular PC visits would have better } \\
\text { outcomes }^{\text {a }} \text { than beneficiaries with less regular PC } \\
\text { visits }\end{array}$ & $\begin{array}{l}\text { Beneficiary-level hypothesis is accepted or } \\
\text { rejected }\end{array}$ \\
\hline Step 7 & Site-level analyses & $\begin{array}{l}\text { Test the site-level hypothesis that sites with more } \\
\text { regular PC visits than predicted would have better } \\
\text { outcomes }{ }^{\text {a }} \text { than sites with less regular PC visits than } \\
\text { predicted based upon beneficiary characteristics }\end{array}$ & $\begin{array}{l}\text { FQHC site-level hypothesis is accepted or rejec- } \\
\text { ted }^{\mathrm{c}}\end{array}$ \\
\hline
\end{tabular}

PC primary care

${ }^{a}$ Better outcomes are defined as fewer ED visits, fewer hospitalizations, and lower total Medicare expenditures

${ }^{b}$ If the hypothesis is accepted, beneficiaries with more regular PC visits had better outcomes than beneficiaries with less regular PC visits

${ }^{C}$ If the hypothesis is accepted, beneficiaries at FQHC sites with more regular PC visits than predicted had better outcomes than beneficiaries at FQHC

sites with less regular PC visits than predicted

Each of these five groups was then subdivided into regular and irregular subgroups according to the observed regularity of the primary care visits. The distinction between regular and irregular subgroups was based on the coefficient of variation $(\mathrm{CoV})$ for the interval between primary care visits. The $\mathrm{CoV}$ is a standard measure of statistical variation calculated by dividing the standard deviation of the visit interval by its mean. ${ }^{10}$ Each group was divided in half, based on whether beneficiaries were above or below the median $\mathrm{CoV}$ value.

Step 3: Calculate the probability for each beneficiary to be assigned to the regular subgroup, as opposed to the irregular subgroup

In Step 3, we calculated the predicted probability that each beneficiary would be assigned to the regular, as opposed to the irregular subgroup, given each beneficiary's characteristics. Conceptually, this resembles any model intended to predict a binary outcome, such as a propensity score or a risk adjustment model. ${ }^{11}$ To accomplish this goal, we created a logistic model to calculate a predicted probability for each beneficiary to be in the regular, as opposed to the irregular subgroup. Based on this model, each beneficiary had a calculated probability between 0 and 1 to be in the regular subgroup - the beneficiary's "expected" probability. Beneficiary characteristics used for this calculation included age, race, gender, disability status, Medicaid eligibility, prior institutionalization, geographic region, rural/urban residence, area socioeconomic status measured using the percentage of households below the federal poverty level in the zip code of residence, ${ }^{12}$ and hierarchical condition category (HCC) scores (a burden of illness measure). ${ }^{13}$

Step 4: Use beneficiary expected probabilities to generate site-level expected probabilities for regular vs. irregular visit patterns

In Step 3, we had calculated the expected probability of being in the regular subgroup for each beneficiary. In Step 4, we summed these expected probabilities for each site to generate an expected proportion of beneficiaries in the regular subgroup at the site level. We repeated this calculation once for each of the five groups within each site.

Step 5: Compare observed and expected site-level visit regularity scores

To capture the degree to which the regularity of a site's primary care visit patterns differ from what would have been predicted based upon the site's beneficiary characteristics, we generated an "observed minus expected score" (O-E score) for each of the five groups at each site. The O-E score is based on the difference between the observed number of beneficiaries in the regular subgroup and the number of beneficiaries predicted to be in the regular subgroup based upon the beneficiaries' demographic and comorbid characteristics. The strategy of comparing sites based on O-E scores is borrowed from the risk adjustment literature ${ }^{11}$ and has been used in other similar studies comparing sites of care. ${ }^{14-16}$ 
Step 6: Compare beneficiary-level outcomes across 10 beneficiary subgroups

We compared the three study outcomes - number of ED visits, number of hospitalizations, and total Medicare expenditures - across the 10 subgroups of beneficiaries, adjusting for beneficiary-level covariates. This step allowed us to test our beneficiary-level hypotheses, namely that beneficiaries with more regular primary care visits would have better outcomes after adjusting for beneficiary-level characteristics.

Step 7: Compare site-level outcomes, stratifying sites based on O-E score

We compared the three study outcomes across FQHC sites, based on site-level tertiles of O-E scores. This step allowed us to test our site-level hypotheses, namely that sites with more beneficiaries than expected in the regular subgroup would have better outcomes, compared to sites with fewer beneficiaries than expected in the regular subgroup.

\section{Variable and Model Specifications}

An ED visit was defined as any visit to an ED, including an observation stay, not resulting in admission. Hospitalization included admissions to acute-care or critical access hospitals. Total Medicare expenditures consisted of inpatient, outpatient, skilled nursing facility, home health, hospice, durable medical equipment, and part B expenditures. These outcomes were observed in year 3, to ensure that they would occur after the categorization of patients based on the regularity of their PC visits. Further details on these three outcomes are found in Online Appendix A.

For the ED visit and hospitalization analyses, we used negative binomial models. A negative binomial model accommodates "count" data in the outcome, but unlike a Poisson model, does not assume that the variance is equal to the mean. This makes it a better model for utilization outcomes, which are often skewed. ${ }^{8,9}$ For the analyses of total Medicare expenditures, we used a gamma generalized linear model with a $\log$ link to accommodate the non-linear nature of cost data. ${ }^{8}$ ${ }^{9}$ For the beneficiary-level analyses, we adjusted for the beneficiary characteristics listed in Table 2 (all variables were modeled as categorical variables). For site-level analyses, we did not adjust for beneficiary characteristics because they were already reflected in O-E score calculations. All analyses were conducted with SAS, version 9.3 (SAS Corporation, Cary, $\mathrm{NC})$.

\section{RESULTS}

Descriptive characteristics of the study sample are shown in Table 2 and reflect the population of FFS Medicare beneficiaries receiving primary care at $\mathrm{FQHC}$ sites: $56 \%$ were over 65 years of age, $50 \%$ were dually eligible for Medicare and Medicaid, and $51 \%$ were disabled. The racial composition of
Table 2 Sample Characteristics $(n=378,862)$

\begin{tabular}{ll}
\hline \hline Characteristic & Percent \\
\hline Demographics & \\
Age & \\
18-44 & $11.6 \%$ \\
45-54 & $14.6 \%$ \\
55-64 & $18.2 \%$ \\
65-74 & $35.0 \%$ \\
75-84 & $15.9 \%$ \\
>=85 & $4.7 \%$ \\
Race/ethnicity & $69.7 \%$ \\
White & $17.7 \%$ \\
Black & $6.9 \%$ \\
Hispanic & $2.9 \%$ \\
Asian & $1.0 \%$ \\
Native American & $1.8 \%$ \\
Other/unknown & \\
Gender & $42.8 \%$ \\
Male & $57.2 \%$ \\
Female & $51.4 \%$ \\
Disabled & $1.5 \%$ \\
Previously institutionalized & $49.5 \%$ \\
Medicaid-eligible & \\
Geographic & \\
Region & $22.7 \%$ \\
Central & $13.1 \%$ \\
Mid-Atlantic & $13.1 \%$ \\
Northeast & $16.5 \%$ \\
Southeast & $15.4 \%$ \\
West & $19.2 \%$ \\
West-central & \\
Urban/rural status, \% & $65.6 \%$ \\
Highly urban & $19.7 \%$ \\
Highly rural & $14.7 \%$ \\
Neither highly urban nor highly rural & \\
Neighborhood socioeconomic status (SES) & \\
Percentage of households below federal poverty & $13.4 \%$ \\
0-9.99\% & $37.3 \%$ \\
10-19.99\% & $26.4 \%$ \\
20-29.99\% & $22.8 \%$ \\
Comorbid conditions & \\
Diabetes & $36.0 \%$ \\
Chronic lung disorders & $16.5 \%$ \\
Severe mental health disorders & $15.3 \%$ \\
Cardiovascular disease & $13.6 \%$ \\
Neurological disorders & $12.2 \%$ \\
Chronic heart failure & $11.9 \%$ \\
Vascular disorders & $10.6 \%$ \\
Renal failure & $10.4 \%$ \\
Cancer & \\
Trauma & \\
Hierarchical condition category (HCC) score, mean (SD) \\
\hline
\end{tabular}

the sample (30\% non-White) was similar to the US population. Beneficiaries had an overall high degree of comorbidity: for example, the average beneficiary had a higher level of comorbidity than the overall Medicare population (HCC score: 1.14).

Table 3 shows how the study sample was split among the 10 subgroups. Within each visit frequency group, regular and irregular subgroups had similar frequency of primary care visits, HCC score, and rates of death during the 4-year study, as expected. These similarities confirmed our decision to consider each visit frequency group as beneficiaries with similar illness burden. Further comparisons of beneficiary characteristics by subgroup are shown in Online Appendix B.

We compared the three study outcomes of ED visits, hospitalizations, and total Medicare expenditures for beneficiaries 
Table 3 Utilization and Mortality for 10 Subgroups of Beneficiaries Based on Frequency and Temporal Regularity of Primary Care Visits (Total $n=378,862$ )

\begin{tabular}{|c|c|c|c|c|c|c|c|c|}
\hline $\begin{array}{l}\text { Visit frequency- } \\
\text { based group } \\
\text { (number) }^{\mathrm{a}}\end{array}$ & $\begin{array}{l}\text { Subgroup } \\
\text { name } \\
\text { (symbol) }^{b}\end{array}$ & $N$ & $\begin{array}{l}\% \text { of } \\
\text { total } \\
\text { sample }\end{array}$ & $\begin{array}{l}\text { Mean number } \\
\text { of primary } \\
\text { care visits/ } \\
\text { year }\end{array}$ & $\begin{array}{l}\text { Coefficient of } \\
\text { variation } \\
(\text { mean)c }\end{array}$ & $\begin{array}{l}\text { Coefficient of } \\
\text { variation } \\
\text { (range) }\end{array}$ & $\begin{array}{l}\text { Average } \\
\text { comorbidity } \\
\text { score }(\mathrm{HCC})\end{array}$ & $\begin{array}{l}\text { Death } \\
\text { before } \\
\text { end of } \\
\text { study }\end{array}$ \\
\hline Least frequent & Regular (1R) & 75,776 & $20 \%$ & 3.3 & 0.5 & $0-0.8$ & 0.8 & $5.7 \%$ \\
\hline visits (1) & Irregular (1I) & 75,775 & $20 \%$ & 3.2 & 1.1 & $0.8-3.0$ & 0.9 & $6.2 \%$ \\
\hline \multirow[t]{2}{*}{ Less frequent (2) } & Regular (2R) & 37,902 & $10 \%$ & 5.3 & 0.6 & $0-0.8$ & 1.1 & $8.4 \%$ \\
\hline & Irregular (2I) & 37,901 & $10 \%$ & 5.3 & 1.1 & $0.8-3.1$ & 1.1 & $8.9 \%$ \\
\hline Moderately & Regular (3R) & 37,887 & $10 \%$ & 7.0 & 0.6 & $0-0.8$ & 1.3 & $11.3 \%$ \\
\hline frequent (3) & Irregular (3I) & 37,886 & $10 \%$ & 7.1 & 1.1 & $0.8-4.0$ & 1.2 & $11.5 \%$ \\
\hline More frequent & Regular (4R) & 28,401 & $7.5 \%$ & 10.1 & 0.7 & $0.04-0.8$ & 1.6 & $17.1 \%$ \\
\hline (4) - 1 & Irregular (4I) & 28,401 & $7.5 \%$ & 10.1 & 1.1 & $0.8-4.1$ & 1.5 & $17.1 \%$ \\
\hline Most frequent & Regular (5R) & 9467 & $2.5 \%$ & 15.5 & 0.6 & $0.01-0.8$ & 2.0 & $28.4 \%$ \\
\hline (5) & Irregular (5I) & 9466 & $2.5 \%$ & 15.8 & 1.2 & $0.8-4.8$ & 2.0 & $31.0 \%$ \\
\hline
\end{tabular}

${ }^{a}$ Group 1 has the lowest frequency of primary care visits, and group 5 the highest

${ }^{b}$ The designation "regular" for a subgroup refers to the half of a group with the lower coefficient of variation, which equates to a more regular pattern of primary care visits, whereas "irregular" refers to higher coefficient of variation/less regularity

${ }^{c}$ Coefficient of variation is defined as the standard deviation of a set of numbers divided by the mean. As such, it is a standardized and unitless number depicting the variation within a set of numbers. Here, it is used to capture the variability of the interval between primary care visits for each beneficiary 'The previous column showed the mean coefficient of variation within each group, this column shows the range within the group

${ }^{e} \mathrm{HCC}$ is a comorbidity score (Pope et al., 2004) designed to predict spending in future years based on comorbidities and demographic information

${ }^{f}$ Percentage of group who died of any cause before the end of the study

categorized within regular and irregular subgroups after adjustment for beneficiary characteristics. Across all five visit frequency groups, the irregular subgroups had worse outcomes than the corresponding regular subgroup (Table 4). For example, among beneficiaries with the most frequent primary care visits (group 5), beneficiaries in the irregular subgroup had 0.38 more ED visits per year, 0.12 more hospitalizations per year, and \$3301 higher total Medicare expenditures per year (16\% higher spending), compared to the regular subgroup ( $p<0.001$ for all three comparisons).

We then modeled the odds for each beneficiary, based on his or her measured characteristics, to be in the regular subgroup (Online Appendix C). We then measured how many beneficiaries each FQHC site had in the regular subgroups compared to what would be expected based on beneficiary characteristics. Sites varied widely in terms of how many beneficiaries were in the regular subgroups compared to how many would have been expected (Online Appendix D).

Table 5 shows the range of O-E scores for each tertile of FQHC sites, as well as the average ED visits, hospitalizations, and total Medicare expenditures per beneficiary for each tertile. Sites in the tertiles with more regular visits than predicted had fewer ED visits per person-year within group 1, group 4, and especially group 5 (difference of $0.29 \mathrm{ED}$ visits per person-year $(p<0.001)$ in group 5 , most frequent visits). Total Medicare expenditures also were lower at better-performing

Table 4 Comparison of 10 Subgroups of Beneficiaries on the Study Outcomes of ED Visits, Hospitalizations, and Total Medicare Expenditures per Beneficiary per Year (Total $n=322,146)$

\begin{tabular}{|c|c|c|c|c|c|c|c|}
\hline $\begin{array}{l}\text { Visit } \\
\text { frequency- } \\
\text { based group } \\
\text { (number) }\end{array}$ & $\begin{array}{l}\text { Subgroup } \\
\text { name } \\
\text { (symbol) }^{a}\end{array}$ & $\begin{array}{l}\text { ED visits } \\
\text { (adjusted } \\
\text { rates) }\end{array}$ & $\begin{array}{l}\text { ED visits } \\
\text { (adjusted }^{\text {difference) }}\end{array}$ & $\begin{array}{l}\text { Hospitalizations } \\
\text { (adjusted rates) }^{d}\end{array}$ & $\begin{array}{l}\text { Hospitalizations } \\
\text { (adjusted } \\
\text { difference) }^{\mathrm{e}}\end{array}$ & $\begin{array}{l}\text { Total Medicare } \\
\text { expenditures } \\
\text { per beneficiary } \\
\text { (adjusted) }^{\mathrm{e}}\end{array}$ & $\begin{array}{l}\text { Medicare } \\
\text { expenditures } \\
\text { difference per } \\
\text { beneficiary } \\
\text { (adjusted) }\end{array}$ \\
\hline Least frequent & Regular & 0.43 & $0.15 \dagger$ & 0.18 & $0.06 \dagger$ & $\$ 6084$ & $\$ 1585 \dagger$ \\
\hline visits & Irregular & 0.57 & & 0.24 & & $\$ 7669$ & \\
\hline Less frequent & Regular & 0.56 & $0.15 \dagger$ & 0.23 & $0.07 \dagger$ & $\$ 7960$ & $\$ 1875 \dagger$ \\
\hline visits & Irregular & 0.70 & & 0.30 & & $\$ 9834$ & \\
\hline Moderately & Regular & 0.72 & $0.16+$ & 0.30 & $0.07 \dagger$ & $\$ 10,317$ & $\$ 1771 \dagger$ \\
\hline frequent visits & Irregular & 0.88 & & 0.37 & & $\$ 12,088$ & \\
\hline More frequent & Regular & 1.02 & $0.22 \dagger$ & 0.42 & $0.09 \dagger$ & $\$ 13,354$ & $\$ 2316 \dagger$ \\
\hline visits & Irregular & 1.24 & & 0.51 & & $\$ 15,670$ & \\
\hline Most frequent & Regular & 1.31 & $0.38 \dagger$ & 0.57 & $0.12 \dagger$ & $\$ 17,430$ & $\$ 3301 \uparrow$ \\
\hline visits & Irregular & 1.70 & & 0.69 & & $\$ 20,731$ & \\
\hline
\end{tabular}

tp $<0.001$

"The designation "regular" for a subgroup refers to the half of each visit frequency-based group with more regular visits than the median, while irregular refers to the half of each visit frequency-based group with a less regular visits than the median

${ }^{b}$ Emergency department (ED) visits and hospitalizations are measured as rates per person year, adjusted for sociodemographic variables and comorbid conditions. ED visits include observation stays. ED visits that led to hospitalizations are not counted as ED visits, only as hospitalizations

${ }^{c}$ Within each visit frequency-based group, statistical tests compare the irregular subgroup with the corresponding regular subgroup, using a negative binomial model to accommodate multiple occurrences

${ }^{d}$ Medicare expenditures are in dollars per person-year

${ }^{e}$ Medicare expenditures are compared using a gamma model because of non-normal distribution 
sites, a finding that held true in every group except group 2. Differences in hospitalization rates were extremely small and not statistically significant.

\section{DISCUSSION}

Using a large dataset of beneficiaries receiving primary care at FQHC sites, we examined whether the temporal regularity of primary care visits was associated with utilization and expenditures at the beneficiary and site levels. At the beneficiary level, among those with a similar frequency of primary care visits, the subgroup with more regular primary care visits had fewer ED visits and hospitalizations, and lower total Medicare expenditures than comparable beneficiaries with a more irregular visit pattern. At the site level, after adjusting for covariates, FQHC sites varied considerably on the proportion of beneficiaries with regular patterns of primary care visits. Sites with higher than expected proportions of beneficiaries with regular visit patterns had fewer ED visits and lower Medicare expenditures on average.

Measures have been developed to capture continuity of care, based on the consistency with which a patient sees the same provider. ${ }^{17,18}$ However, to our knowledge, ours is the first measure of the temporal regularity of primary care visits, and it may add a new and measurable dimension to how we

Table 5 Comparison of Beneficiary-Level Outcomes Between Sites with Differing O-E Scores on Regularity of Care

\begin{tabular}{|c|c|c|c|c|c|c|c|c|}
\hline $\begin{array}{l}\text { Visit } \\
\text { frequency- } \\
\text { based } \\
\text { group }\end{array}$ & $\begin{array}{l}\text { Site-level } \\
\text { tertile of } \\
\text { regularity } \\
\text { compared } \\
\text { to } \\
\text { predicted }^{\text {a }}\end{array}$ & $\begin{array}{l}\begin{array}{l}\text { Range } \\
\text { of site- } \\
\text { level } O-\end{array} \\
\mathbf{E} \\
\text { scores }^{\mathbf{b}}\end{array}$ & $\begin{array}{l}\text { ED } \\
\text { visits }^{c}\end{array}$ & $\begin{array}{l}\text { ED visits } \\
\text { (difference) }^{d}\end{array}$ & Hospitalizations $^{\mathrm{c}}$ & $\begin{array}{l}\text { Hospitalizations } \\
\text { (difference) }^{\mathrm{d}}\end{array}$ & $\begin{array}{l}\text { Total } \\
\text { Medicare } \\
\text { expenditures } \\
\text { per } \\
\text { beneficiary }\end{array}$ & $\begin{array}{l}\text { Difference in } \\
\text { Medicare } \\
\text { expenditures } \\
\text { per } \\
\text { beneficiary }\end{array}$ \\
\hline \multirow{3}{*}{$\begin{array}{l}\text { Least } \\
\text { frequent } \\
\text { visits }\end{array}$} & $\begin{array}{l}\text { Tertile } 1 \\
\text { (more) }\end{array}$ & $\begin{array}{l}(3.7 \\
39.3)\end{array}$ & 0.48 & REF & 0.19 & REF & $\$ 6513$ & REF \\
\hline & $\begin{array}{l}\text { Tertile } 2 \\
\text { (similar) }\end{array}$ & $\begin{array}{l}(-7.3 \\
3.7)\end{array}$ & 0.52 & $0.04 \dagger$ & 0.20 & 0.00 & $\$ 6730$ & $\$ 217^{*}$ \\
\hline & $\begin{array}{l}\text { Tertile } 3 \\
\text { (less) }\end{array}$ & $\begin{array}{l}(-45.1 \\
-7.3)\end{array}$ & 0.52 & $0.03 \dagger$ & 0.20 & $0.01 *$ & $\$ 7008$ & $\$ 495 \dagger$ \\
\hline \multirow{3}{*}{$\begin{array}{l}\text { Less } \\
\text { frequent } \\
\text { visits }\end{array}$} & $\begin{array}{l}\text { Tertile } 1 \\
\text { (more) }\end{array}$ & $\begin{array}{l}(5.0 \\
48.4)\end{array}$ & 0.64 & REF & 0.26 & REF & $\$ 8651$ & REF \\
\hline & $\begin{array}{l}\text { Tertile } 2 \\
\text { (similar) }\end{array}$ & $\begin{array}{l}(-9.3 \\
5.0)\end{array}$ & 0.65 & 0.01 & 0.26 & 0.00 & $\$ 8647$ & $-\$ 4$ \\
\hline & $\begin{array}{l}\text { Tertile } 3 \\
\text { (less) }\end{array}$ & $\begin{array}{l}(-51.8 \\
-9.3)\end{array}$ & 0.64 & 0.00 & 0.26 & 0.00 & $\$ 8879$ & $\$ 228$ \\
\hline \multirow{3}{*}{$\begin{array}{l}\text { Moderately } \\
\text { frequent } \\
\text { visits }\end{array}$} & $\begin{array}{l}\text { Tertile } 1 \\
\text { (more) }\end{array}$ & $\begin{array}{l}(4.3 \\
38.7)\end{array}$ & 0.80 & REF & 0.32 & REF & $\$ 10,887$ & REF \\
\hline & $\begin{array}{l}\text { Tertile } 2 \\
\text { (similar) }\end{array}$ & $\begin{array}{l}(-8.3 \\
4.3)\end{array}$ & 0.82 & 0.02 & 0.33 & 0.01 & $\$ 10,926$ & $\$ 39$ \\
\hline & $\begin{array}{l}\text { Tertile } 3 \\
\text { (less) }\end{array}$ & $\begin{array}{l}(-43.3 \\
-8.3)\end{array}$ & 0.81 & 0.01 & 0.34 & 0.01 & $\$ 11,286$ & $\$ 399 *$ \\
\hline \multirow{3}{*}{$\begin{array}{l}\text { More } \\
\text { frequent } \\
\text { visits }\end{array}$} & $\begin{array}{l}\text { Tertile } 1 \\
\text { (more) }\end{array}$ & $\begin{array}{l}(4.5, \\
43.3)\end{array}$ & 1.10 & REF & 0.46 & REF & $\$ 13,876$ & REF \\
\hline & $\begin{array}{l}\text { Tertile } 2 \\
\text { (similar) }\end{array}$ & $\begin{array}{l}(-7.5 \\
4.5)\end{array}$ & 1.16 & $0.06^{*}$ & 0.44 & -0.02 & $\$ 14,239$ & $\$ 363$ \\
\hline & $\begin{array}{l}\text { Tertile } 3 \\
\text { (less) }\end{array}$ & $\begin{array}{l}(-45.5 \\
-7.5)\end{array}$ & 1.16 & $0.06^{*}$ & 0.47 & 0.01 & $\$ 14,514$ & $\$ 639 \dagger$ \\
\hline \multirow{3}{*}{$\begin{array}{l}\text { Most } \\
\text { frequent } \\
\text { visits }\end{array}$} & $\begin{array}{l}\text { Tertile } 1 \\
\text { (more) }\end{array}$ & $\begin{array}{l}(4.9 \\
32.8)\end{array}$ & 1.18 & REF & 0.53 & REF & $\$ 15,550$ & REF \\
\hline & $\begin{array}{l}\text { Tertile } 2 \\
\text { (similar) }\end{array}$ & $\begin{array}{l}(-10.1, \\
4.9)\end{array}$ & 1.47 & $0.29 \dagger$ & 0.57 & 0.03 & $\$ 19,041$ & $\$ 3491 \dagger$ \\
\hline & $\begin{array}{l}\text { Tertile } 3 \\
\text { (less) }\end{array}$ & $\begin{array}{l}(-42.9 \\
-10.1)\end{array}$ & 1.47 & $0.29 \dagger$ & 0.56 & 0.03 & $\$ 17,898$ & $\$ 2348 \dagger$ \\
\hline \multirow[t]{3}{*}{$\begin{array}{l}\text { All groups } \\
\text { combined }\end{array}$} & $\begin{array}{l}\text { Tertile } 1 \\
\text { (more) }\end{array}$ & $\begin{array}{l}(2.7 \\
43.3)\end{array}$ & 0.70 & REF & 0.29 & REF & $\$ 9406$ & REF \\
\hline & $\begin{array}{l}\text { Tertile } 2 \\
\text { (similar) }\end{array}$ & $\begin{array}{l}(-7.7 \\
2.7)\end{array}$ & 0.74 & $0.04 \dagger$ & 0.29 & 0.00 & $\$ 9536$ & $\$ 130^{*}$ \\
\hline & $\begin{array}{l}\text { Tertile } 3 \\
\text { (less) }\end{array}$ & $\begin{array}{l}(-45.1 \\
-7.7)\end{array}$ & 0.73 & $0.03 \dagger$ & 0.29 & 0.00 & $\$ 9562$ & $\$ 156^{*}$ \\
\hline
\end{tabular}

$* p<0.05 ; t p<0.001$

${ }^{a}$ Within each group, Tertile 1 has primary care visits that are more regular than expected, Tertile 2 has regularity similar to expected, and Tertile 3 has regularity less than expected

${ }^{b}$ Range of $O-E$ scores for the sites in each tertile. A positive $O$-E score means that the site had more beneficiaries in the regular group than expected. A negative $O-E$ score means that the site had fewer beneficiaries in the regular group than expected. An O-E score close to zero means that the site had only a minimal difference between the observed and expected

${ }^{c}$ Emergency department (ED) visits and hospitalizations are measured as rates per person year, adjusted for sociodemographic variables and comorbid conditions. ED visits include observation stays. ED visits that led to hospitalizations are not counted as ED visits, only as hospitalizations

${ }^{d}$ Within each visit frequency-based group, statistical tests compare the irregular subgroup with the corresponding regular subgroup (e.g., comparing group 11 with 1R), using a negative binomial model to accommodate multiple occurrences

${ }^{e}$ Medicare expenditures are in dollars per person-year

${ }^{f}$ Medicare expenditures are compared using a gamma model because of non-normal distribution 
think about continuity of care. Temporal regularity was associated with outcomes not only at the individual patient level but also at the site of care level. The effect sizes were smaller when measured at the site of care level. This fits with the usual pattern for a quality measure, in that the most direct impact is seen at the patient level, with progressively more attenuated effects seen at higher levels of aggregation (provider, site, health plan). ${ }^{19,20}$

There are at least two possible explanations for why we found that a more temporally regular pattern of primary care visits is associated with better outcomes. Our primary hypothesis is that a more temporally regular pattern of visits reflects higher quality of care at some sites, achieved through more effective efforts to manage patients proactively and conversely to prevent loss to follow-up. However, a second possibility also exists, namely that temporal regularity is capturing unmeasured patient-level variables that are associated with risk for poor outcomes, such as a patient's propensity to attend scheduled appointments or to participate in other healthpromoting activities. In future work, we plan to investigate the extent to which each of these hypotheses is true.

If we were to find that temporal variability of primary care visits is capturing quality of care, a logical next step would be to institute a program of quality measurement and quality improvement. Sites whose patterns of care are the most irregular might pursue steps to improve the regularity of visits; however, this would first require additional investigation to understand differences in organization and process of care that allow some sites to achieve greater regularity of primary care visits.

On the other hand, if we were to find that temporal regularity is primarily capturing other unmeasured patientlevel variables, it would seem to be the case that whatever it is capturing is strongly associated with outcomes. As an example of where this measure might be useful, there is a large body of literature based on creating better models to predict future costs. ${ }^{21}$ Our study suggests that adding a measure of temporal variability could improve these models. In this case, a logical next step for research would be to examine the incremental contribution to prediction of these events through a statistic such as change in the area under the curve, integrated discrimination improvement, or net reclassification improvement. ${ }^{22}$

Our study has several limitations. First, we cannot yet say whether the new measure we describe is reflecting quality of care, unmeasured patient-level confounders, or both to some extent. One priority for future research will be to examine this question. However, the similar findings from both individuallevel and site-level analysis make it seem less likely that unresolved confounding is accounting for the entire effect that we observed.

Second, in the event that we do eventually find that this new measure is primarily capturing quality of care, it would also remain important to understand exactly how sites may contribute to regular patterns of primary care, although we do have some hypotheses described above. A follow-up study, with direct observation of care at sites whose temporal patterns of care are markedly more or less regular than predicted, could shed light on how this phenomenon occurs. ${ }^{23}$

Third, this study only used data from Medicare FFS beneficiaries, all of whom received primary care from $\mathrm{FQHC}$ sites. It is not clear how these phenomena would translate to other individuals. FQHC beneficiaries may have been an ideal population in which to demonstrate these concepts, because they may have an especially high degree of illness burden and life challenges.

Finally, there were constraints on our ability to show effects at the site of care level, most importantly because beneficiaries can move away from the practice to which they were initially attributed. We used an intent-to-treat analysis, keeping beneficiaries with the site to which they were initially attributed. However, only $65.5 \%$ of beneficiaries in the outcomes analysis were attributed to their "home" FQHC site during any quarter of year 3 of our study. This would tend to diminish any impact that excellent (or poor) sites could have on outcomes.

Despite these limitations, we found that the temporal pattern of primary care visits is an important way to characterize beneficiaries, beyond what can be known from measures like comorbidity score and frequency of primary care visits. We have also shown that there are site-level differences on regularity of primary care visits, even after adjusting for beneficiary characteristics, and that these differences have implications for outcomes. After additional work to understand exactly what construct is being measured, a pattern of irregularly spaced primary care visits could potentially help identify beneficiaries for extra attention, or could serve as an important target for site-level quality improvement efforts.

Acknowledgements: We thank Suzanne Wensky and Katherine Giuriceo of the Center for Medicare and Medicaid Innovation for their helpful comments on prior drafts of this manuscript.

Corresponding Author: Adam J. Rose, MD MSc FACP; RAND Corporation, Boston, MA, USA (e-mail: arose@rand.org).

Funding This study was supported by contract HHSM-500-2005$00028 \mathrm{I}$ with the Centers for Medicare and Medicaid Services.

\section{Compliance with Ethical Standards:}

Conflict of Interest: The authors declare that they do not have a conflict of interest.

Disclaimer: The opinions expressed in this publication do not necessarily reflect the official policies of the Centers for Medicare and Medicaid Services.

\section{REFERENCES}

1. Bodenheimer T, Wagner EH, Grumbach $\mathbf{K}$. Improving primary care for patients with chronic illness. J Am Med Assoc. 2002;288:1775-1779.

2. Shi L. Primary care, specialty care, and life chances. Int J Health Serv. 2002;24:431-548.

3. Starfield B, Shi L, Macinko J. Contribution of primary care to health systems and health. Milbank Q. 2005;83:457-502. 
4. Shi L, Starfield B. Primary care, income inequality, and self-rated health in the united states: a mixed-level analysis. Int $J$ Health Serv. 2000;30:541-555.

5. Shi L, Starfield B. The effect of primary care physician supply and income inequality on mortality among Blacks and Whites in US Metropolitan areas. Am J Public Health. 2001;91:246-250.

6. Starfield B, Shi L. Policy relevant determinants of health: an international perspective. Health Policy. 2002;60:201-18.

7. Wagner EH, Austin BT, Von Korff M. Organizing care for patients with chronic illness. Milbank Q. 1996;74:511-544.

8. Kahn KL, Timbie JW, Friedberg MW, et al. Evaluation of CMS's Federally Qualified Health Center (FGHC) Advanced Primary Care Practice (APCP) Demonstration: Final Report. Santa Monica: RAND Corporation, 2017. Available at: https://www.rand.org/pubs/research reports/RR886z2.html. Accessed October 10, 2018.

9. Timbie JW, Setodji CM, Kress A, et al. Implementation of medical homes in federally qualified health centers. N Engl J Med. 2017;377:246-256.

10. Lindgren B. W. 1960. Statistical theory. Macmillan, New York

11. Iezzoni LI. 2003. Risk adjustment for measuring health care outcomes, 3. Chicago: Health Administration Press.

12. Bird CE, Seeman T, Escarce JJ, et al. Neighbourhood socioeconomic status and biological 'wear and tear' in a nationally representative sample of US adults. J Epidemiol Community Health. 2010;64:860-865

13. Pope GC, Kautter J, Ellis RP, et al. Risk adjustment of medicare capitation payments using the CMS-HCC model. Health Care Financ Rev. 2004;25:119-141.

14. Berlowitz DR, Ash AS, Hickey EC, et al. Inadequate management of blood pressure in a hypertensive population. N Engl J Med. 1998;339: 1957-1963.

15. Hong CS, Atlas SJ, Chang Y, et al. Relationship between patient panel characteristics and primary care physician clinical performance rankings. JAMA. 2010;304:1107-1113.

16. Zaslavsky AM, Hochheimer JN, Schneider EC, et al. Impact of sociodemographic case mix on the HEDIS measures of health plan quality. Med Care. 2000;38:981-992.

17. Bice TW, Boxerman SB. A quantitative measure of continuity of care. Med Care. 1977;43:1130-1139.

18. Breslau N, Reeb KG. Continuity of care in a university-based practice. J Med Educ. 1975;50:965-969.

19. Cancino RS, Hylek EM, Reisman JI, Rose AJ. Comparing patient-level and site-level anticoagulation control as predictors of adverse events. Thromb Res. 2014;4:652-656.

20. Hofer TP, Hayward RA, Greenfield S, Wagner EH, Kaplan SH, Manning WG. The unreliability of individual physician "report cards" for assessing the costs and quality of care for a chronic disease. JAMA. 1999;281:2098-2105.

21. Ash AS, Ellis RP, Pope GC, et al. Using diagnoses to describe populations and predict costs. Health Care Financ Rev. 2000;21:7-28.

22. Pencina MJ, D’Agostino RB, Pencina KM, Jassens ACJW, Greenland $\mathbf{P}$. Interpreting incremental value of markers added to risk prediction models. Am J Epidemiol. 2012;176:473-481.

23. Rose AJ, McCullough MB. A practical guide to using the positive deviance method in health services research. Health Serv Res. 2017;52:1207-1222 